Buying what people like you buy:

Personality Homophily and Well-being in Consumer Behaviour

\author{
Rosa Lavelle-Hill \\ The Alan Turing Institute, UK \\ rlavelle-hill@turing.ac.uk \\ James Goulding \\ N/LAB, Nottingham University Business School, UK \\ james.goulding@nottingham.ac.uk
}

Anya Skatova

School of Experimental Psychology, University of Bristol, UK

David Clarke

School of Psychology, University of Nottingham, UK

Pete Bibby

School of Psychology, University of Nottingham, UK 


\begin{abstract}
Recommender systems and personalised marketing algorithms now proliferate our daily lives, harnessing similarity to other profiles to guide our purchasing decisions. Recent research indicates that this personalisation can be good for our well-being, as spending in a way that fits our personality, can engender happiness. Less well-understood however, is the impact personality homophily (where people prefer to connect with others of similar personalities) has on consumer well-being. In this study, we investigate whether individuals who exhibit homophily in their consumption patterns, by buying what others of a similar personality buy, report higher well-being. We analyse over 12,000 personality questionnaires measuring the Big Five and well-being, linked to 3 million loyalty card transaction logs from a multi-national retailer. Personality homophily, or 'buying what people like you buy', is quantified by introducing a novel metric, Personality Alignment (PA). Findings show that PA on Extroversion, Agreeableness, and Neuroticism positively predicts well-being, and that effects are strongest for those higher in Neuroticism. Given the rise of algorithm-assisted decision making, along with growing attention to ethical-AI, these results show that personality homophily can be leveraged in the design of future personalised marketing mechanisms, not just for greater sales, but also customer's long term well-being.
\end{abstract}




\section{Buying what people like you buy: Personality Homophily and Well-being in Consumer Behaviour}

\section{Introduction}

The set of products we desire as consumers is not always commensurate with the set of products that would maximise our well-being. Consumption of high-sugar foods, fast-fashion and expensive brands are often testament to this. Maximising long-term happiness has always been within the purview of consumers themselves and outside the remit of businesses, where marketing efforts understandably focus on maximising customer spend and short-term purchase satisfaction. However, this traditional delineation of responsibilities is now being opened to question due to the fundamental shifts that have occurred in targeted marketing over the last decade (Frischmann \& Selinger, 2018). Increasing availability of mass transactional data records has led to the rapid proliferation of Recommender Systems and Personalized Marketing algorithms, tailoring the adverts we see and guiding the purchasing decisions we make. In many ways, consumers are gradually ceding decision-making responsibilities to automated algorithms, shifting to a form of 'exogenous cognition' in response to overwhelming product choice (Smith, 2019). Consumption decisions are no longer just supported by external algorithms, but often directly mediated by them; and while not all marketing processes are susceptible to this relentless automation, those that are will likely deepen as we embed further in the 'Internet of things'.

\section{Spending, Well-being and Personality}

As a consequence of this shift, the impact consumption has on subjective well-being and mental health is of increasing relevance within consumer psychology (Diener \& Seligman, 2004; Gilovich, Kumar, \& Jampol, 2015a, 2015b; Matz, Gladstone, \& Stillwell, 2016; Pham, 2015; Schmitt, Brakus, \& Zarantonello, 2015). The relationship between purchases and long-term happiness is a complex one, but recent studies indicate that consumer spend can increase well-being if that spending occurs in the 'right' way (Dunn, Gilbert, \& Wilson, 2011). But what the 'right' way is, is likely 
dependent on the characteristics of the individual. Studies have shown that individual differences mediate the effect of purchasing on happiness. Zhang, Howell, Caprariello, and Guevarra (2014) showed that experiential purchases bought a greater amount of happiness to 'experiential' people; and Hill and Howell (2014) found that 'gifting' improves the well-being only for those who are more sensitive to other's needs.

The five factor model of personality (or the 'Big Five') (Costa \& McCrae, 1985; Goldberg, 1992; McCrae \& John, 1992; Saucier, 1994) is the most well established and widely used. It proposes that personality can be expressed along five trait dimensions: Openness to new experiences (intellectual, complex); Conscientiousness (dependable, self-disciplined); Extroversion (fun, enthusiastic); Agreeableness (sympathetic, warm); and Neuroticism (anxious, easily upset) (Gosling, Rentfrow, \& Swann Jr, 2003). Matz et al. (2016) used this model and Amazon Turks to rate spending categories' 'personality', to show that well-being can be predicted by the 'psychological fit' of the shopping to the customer's own personality. Simply put, consumers who buy products that match their personalities appear, in general, to be happier.

\section{Personality Homophily and Consumption}

'Personality homophily' has been linked to well-being in several domains. This study, however, reflects the first time it has been investigated in the field of consumer psychology. Homophily is the term used when people prefer to connect with similar others, and has been observed across a number of dimensions (Rushton \& Bons, 2005), including psychological ones (McPherson, Smith-Lovin, \& Cook, 2001). Wu, Stillwell, Schwartz, and Kosinski (2017) showed a strong personality homophily effect in couples and friends, using behaviour and language assessments of personality (to remove the reference-group effect (Heine, Lehman, Peng, \& Greenholtz, 2002) that occurs with self-report measures) to show that people with similar personalities 'flock together'. Noë, Whitaker, and Allen (2016) provided evidence for the effect in social networks, showing that those who were more similar on the traits Agreeableness, Conscientiousness and Extroversion, had stronger connections. 
Geographical personality homophily has also been observed. Noë, Whitaker, Chorley, and Pollet (2016) found that people with similar levels of Openness, Conscientiousness or Agreeableness preferentially visited common locations in their daily lives. In (Noë, Whitaker, \& Allen, 2018) it was further shown that people with similar levels of Extroversion lived in closer physical proximity to each other. Interestingly, a reverse effect was found for those who were similar on traits Openness and Conscientiousness, indicating that personality homophily effects are not uniform across all Big Five traits dimensions.

Most recently, research has also shown that personality homophily can be related to both happiness (Jokela, Bleidorn, Lamb, Gosling, \& Rentfrow, 2015) and success (Laakasuo et al., 2020). Jokela et al. (2015) not only found clusters of similar personality traits in London, but that when people in those clusters had a similar level of openness to those around them, they were happier. In this paper, we theorise that people who show homophily in a consumer context, shopping in harmony with others of a similar personality, will show increased well-being.

\section{Collaborative Filtering, Personality and Well-being}

Investigating the homophily effect in consumption patterns draws parallels with the principles already employed by recommender systems Su and Khoshgoftaar (2009). Such algorithms often use a technique called Collaborative Filtering (CF), which derives product recommendations by finding similarities between users (Linden, Smith, \& York, 2003). The similarity metric most commonly used compares customers' purchase histories to one another, following the logic that those who have bought similar things in the past are more likely to buy similar things in the future. While personality is not considered, homophily of behaviour remains exploited - and links between well-being and homophily therefore have implications for the responsible design of such algorithms, especially in light of their increasing influence over consumer decision-making.

Despite proving highly successful in adjacent fields such as target marketing (Matz, Kosinski, Nave, \& Stillwell, 2017; Matz, Segalin, Stillwell, Müller, \& Bos, 2019), 
a lack theoretical grounding has meant that the integration of personality into collaborative filtering has remained broadly under-examined, outside of some initial exploration by Tkalcic, Kunaver, Tasic, and Košir (2009). A recent study by Khwaja, Ferrer, Iglesias, Faisal, and Matic (2019), however, indicated the potential benefits, showing that individuals well-being can be bolstered through the recommendation of daily activities that align with their personality.

\section{Research Overview}

This study draws together these three research strands to ask the question: are individuals who exhibit personality homophily in their shopping patterns happier than those that don't? To investigate this, we analyse loyalty card logs of over 12,000 customers from a major multinational retailer, which we linked to survey scores obtained for both the Big Five and subjective well-being.

Detecting personality homophily in transactional data requires design of a new metric, that can measure the extent to which an individuals' consumption patterns match others with similar personality. To achieve this, we first introduce the concept of a product/brand's Expected Personality of Purchase (EPP). EPP is calculated, for each of the Big Five traits, as the average trait values of all individuals purchasing that product/brand, weighted by their frequency of purchase. By calculating EPPs for the top 100 product categories and 100 brands, it is then possible to analyse a person's overall shopping behaviour and assign an expected personality score to it. The difference between this score and their actual reported personality reflects a measure of homophily. We denote this as personality alignment (PA). If PA is large, then an individual is purchasing in line with other people of the same personality type (i.e. they exhibit personality homophily in their consumption behaviour).

This PA metric can then be used to investigate whether homophily predicts greater well-being in a consumer context. This data-driven approach contrasts with previous analyses such (Matz et al., 2016) as it circumvents need for products/brands to be conferred with their own personalities using human-raters. 
The literature on personality homophily suggests that the effect on well-being may not be equal, or even present, for all personality traits (Jokela et al., 2015; Noë, Whitaker, Chorley, \& Pollet, 2016). This study therefore also extends previous work on psychological-fit to shopping, by investigating the homophily effect for each trait individually. The interactions between PA and the Big Five are also investigated to explore whether PA affects well-being more or less for certain personality types. While this research has application to the field of homophily research, it also has relevance to the development of recommender systems, raising the question whether algorithms should be responsibly considering personality to optimise for individuals' long term well-being, as well the likelihood of a sale.

\section{Method}

\section{Participants}

Members of a large health and beauty retailer's customer panel completed an online survey, which included self-reported measures of personality, well-being and demographic questions. They provided permission through informed consent for the retrieval of four years of their loyalty card transaction data. Transaction data and survey data were pseudo-anonymized by a third party to allow the questionnaire responses to be linked to the individual's loyalty card number, at which point it was fully anonymized prior to the analysis. No identifying information was retained, and no incentives were offered for taking part in the study. Full ethical approval was attained prior to the surveys being distributed. Of the 80,000 surveys sent to the retailer's internal consumer panel, 12,968 surveys were returned fully completed and linked to participants' purchasing data (a total of 3.1 million transactions). The first analysis used participants who had bought at least one of the 100 most popular brands $(N=12,167)$. Of these, 11,094 (91\%) of the respondents were female and 1,073 (9\%) were male. The second analysis used participants who had bought from at least one of the 100 most popular product categories $(N=12,230)$. Of these people, 11,158 (91\%) were female and 1,072 (9\%) were male. 


\section{Materials}

To measure respondents' personality the Ten-Item Personality Inventory (TIPI) (Gosling et al., 2003) was used, measuring the Big Five traits (McCrae \& John, 1992) on a 7-point Likert scale. Subjective well-being was measured using two questions: "Overall, how satisfied are you with your life nowadays?" and "Overall, how happy did you feel yesterday?" both on a scale of 0-10. Similar to Longo, Coyne, Joseph, and Gustavsson (2016), the happiness and satisfaction measures used were highly correlated $(r=0.79)$, and were therefore averaged to create a single well-being variable. To measure income, respondents reported whether their annual household income fell into one of eight categories: Less than $£ 25,000, £ 25,000$ to $£ 34,999, £ 35,000$ to $£ 49,999, £ 50,000$ to $£ 74,999, £ 75,000$ to $£ 99,999, £ 100,000$ to $£ 149,999, £ 150,000$ or more, or "Prefer not to say". The link to the full questionnaire can be found in Section D of the Supplementary Materials.

The brand and product categories were predefined by the retailer themselves, and recorded within the transaction data. For the analysis using brands, top-level brand names were leveraged (i.e. no sub-brands). For the product analysis, a finer level of product category descriptors was chosen than in previous work (Matz et al., 2016). For example, where Matz et al. (2016) used spending categories such as 'Dental Care', this analysis used the following set of product categories: Toothbrushes, Dental Floss/Tape, Toothpaste, Dental Accessories and Mouth Fresheners. The full list of brand and product categories can be found in Tables 3 and 4 of the Supplementary Materials.

\section{Calculation of Personality Alignment (PA)}

To investigate whether shopping in alignment with others of similar personality indicates increased happiness, two different consumer behaviours are considered: 1) what brands people buy, and 2) what products people buy. To measure homophily in these consumer behaviours, we now formally introduce the new measure, Personality Alignment (PA). PA represents the distance between an individual's own personality, and the one reflected by their shopping portfolio, as derived by observing the 
personalities of other shoppers who purchased the same products/brands.

To calculate PA, first we derived the Expected Personality of Purchase (EPP) of a range of products and brands sold by the retailer. For a product/brand, $x$, EPP is found by simply observing all the customers who buy that product, and calculating a weighted average of some personality trait $(P)$, as show in Equation 1 below:

$$
E P P_{x}=\sum_{i=1}^{M}\left(\frac{\text { purchases }_{x, i}}{\text { purchases }_{x}} \times P_{i}\right)
$$

Here $M$ is the total number of customers who've ever purchased the product/brand. Note that a weighting factor is applied for each individual $(i)$, based on the number of times they purchased the product $\left(\right.$ purchase $\left._{x, i}\right)$ divided by the overall sales for that item $\left(\right.$ purchase $\left._{x}\right)$. Therefore, the personality of someone who frequently buys a brand or product contributes more to its EPP. As the goal was to study the effect of PA on each trait separately $\left(\mathrm{PA}^{T}\right)$, EPP is calculated 5 times, once for each of the Big Five $(\mathrm{O}, \mathrm{C}, \mathrm{E}, \mathrm{A}$, and $\mathrm{N})$. Importantly, using this method of calculating EPPs, at no point do we confer a product/brand with a personality of its own (as other studies have (Matz et al., 2016)). EPP is purely a statistical expectation. If someone purchased a product, and we had no other knowledge about them, the product's EPP would reflect a 'best guess' prediction of that individual's personality trait values.

Once the EPP scores for each product/brand were calculated, we aggregated them across the items in a person's shopping portfolio to get an overall expectation of each individual's shopping's personality, as reflected by their purchases. We then compared this to the customer's actual personality, which then quantifies their homophily with others. This produces our measure of Personality Alignment (PA), which is formally calculated as the absolute difference between a person's actual personality $\left(P_{i}\right)$ on some trait, $T$, and the EPPs of the products/brands they bought. This is detailed in Equation 2 below, and the overarching process illustrated in Figure 1, which visually shows the steps taken to calculate PA. 


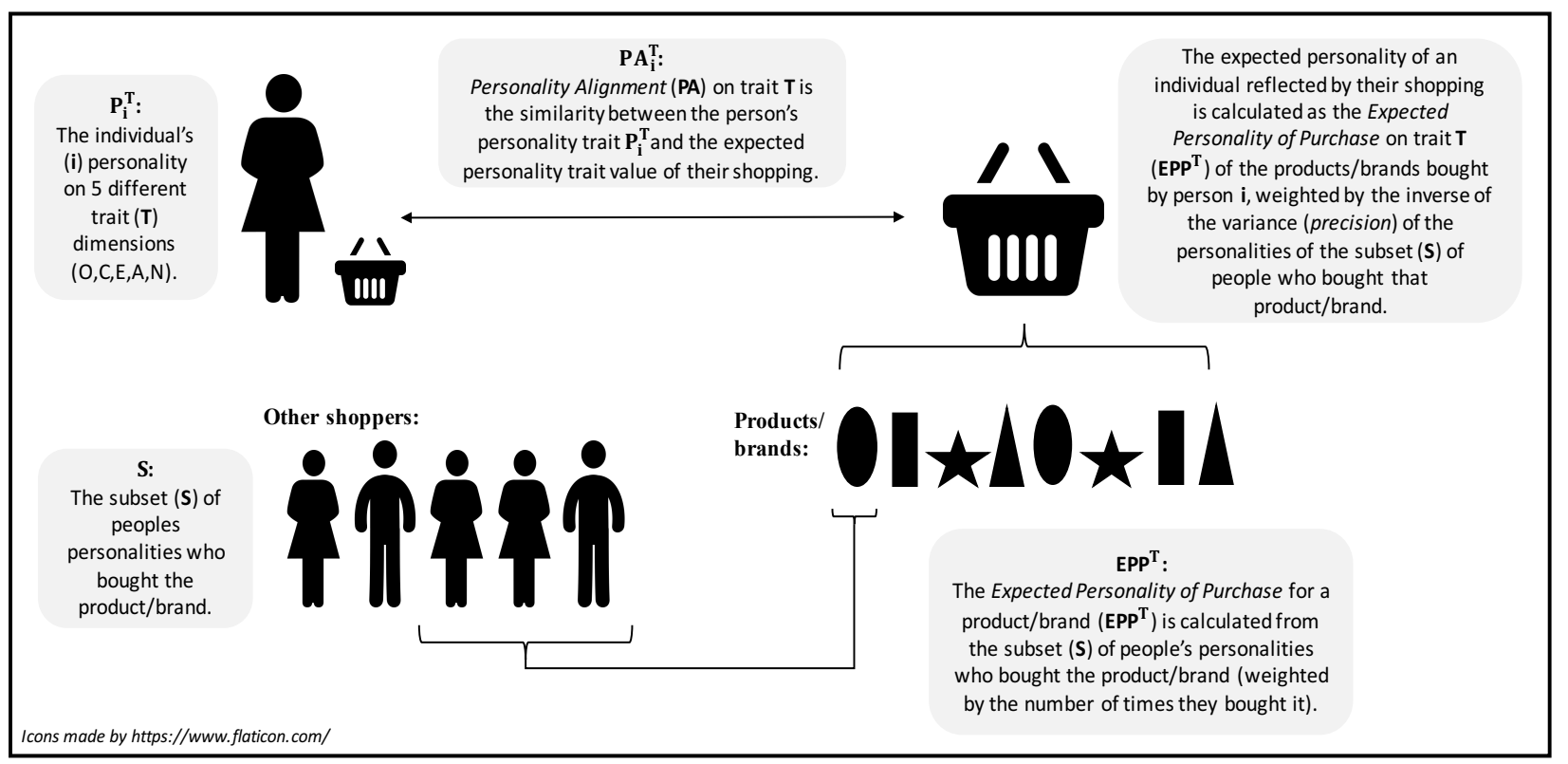

Figure 1. Illustration of the method used to calculate personality alignment (PA) and Expected Purchase Personality (EPP)

In calculating PA, one final step must be employed to account for the fact that some products EPPs are far better predictors of personality than others. Consider a product such as toothpaste, which is broadly purchased by everyone regardless of their personality. Such a product has an extremely high variance in the traits of people who purchase it, and because of this its EPP will reflect the average trait score across the whole population, making it an imprecise indicator of personality. Other products however have tight variances, making them very precise indicators of the traits of those that purchase them. To incorporate this phenomena, we weighted the contribution of each product's EPP by its precision. This meant we divided by the variance observed in trait $T$ for the set of people, $S_{x}$, who bought the product. By integrating this weighting into the PA calculation, we ensured a greater importance was assigned to those products/brands that were better at characterising a particular personality type. With this adjustment, the final measure of homophily was attained:

$$
P A_{i}=\text { mean }-\sum_{x=1}^{X}\left|\frac{P_{i}-E P P_{x}}{\sigma_{S_{x}}^{2}}\right|
$$

Note that to facilitate easier interpretation, we have also subtracted the score 
from the mean, so that higher scores for personality alignment indicate greater homophily. For each individual in our study, we used Equation 2 to calculate their homophily on all five trait's, generating five PA scores for brands (analysis 1), and five for products (analysis 2). Only the top one hundred of the retailer's best-selling brands and products were used in this calculation. This was to ensure EPPs were calculated from a large enough sample of purchases to produce robust estimates.

\section{Predicting Spending}

Before using the PA metric to predict well-being, it was first validated by testing whether people spent more on the brands and products bought by people with a similar personality to themselves. To do this, hierarchical linear regressions with random intercepts for the brands/products were used. The results showed that people did spend more on products and brands purchased by people with similar personalities, when demographics and brand/product personality were controlled for. Therefore, people do spend more money on what people with a similar personality buy. Full results are available in the Section A of the Supplementary Materials. In the next section the investigation into whether the PA metric is associated with greater well-being is presented.

\section{Results}

\section{Analysis 1: Brands}

A sample of 12,172 individuals had bought from at least one of the 100 most popular brands, resulting in 2,589,085 individual transactions. The mean number of unique brands people bought from the top 100 was $33.68(S D=15.95)$, and the mean number of items people bought from each brand was $6.36(S D=14.89)$. See Table 1 for the descriptive statistics for age, average monthly spending, the Big Five, and well-being. Additionally, the personality trait density distributions are available in the Figure 1 in the Supplementary Materials.

To investigate how PA, calculated using the brands people buy, relates to 
well-being, three hierarchical linear regression models were performed. Model 1 was the baseline model with age, gender, income, average monthly spending, and the individual's personality traits as control variables. Model 2 included the addition of PA (for each of the Big Five traits separately). And Model 3 additionally input the interaction between the person's personality and PA on that trait. This was to additionally study whether the effect of PA on well-being was different for different personalities. The variance explained by each model, the model comparison statistics, as well as the unstandardised regression coefficients and confidence intervals can be viewed in Table 3 .

In Model 1, the baseline model, all variables significantly predicted well-being. In Model 2, the addition of PA variables significantly improved the prediction of well-being. Interestingly, only PA on trait Extroversion $\left(\mathrm{PA}^{E}\right), \mathrm{PA}$ on trait Agreeableness $\left(\mathrm{PA}^{A}\right)$ and $\mathrm{PA}$ on trait Neuroticism $\left(\mathrm{PA}^{N}\right)$ were significant predictors of well-being. Therefore, buying the same brands that people who have similar levels of Extroversion, Agreeableness, and Neuroticism buy, predicts greater well-being. In Model 3, it was investigated whether this effect was dependent on the individual's personality traits. Model 3 shows that there is a significant interaction between $\mathrm{PA}^{N}$ and Neuroticism. This interaction is plotted in Figure 2a. The interaction graph shows that the effect of PA on well-being is greater for people who are highly neurotic. When the interaction effects were added in Model 3, the $\mathrm{PA}^{A}$ and $\mathrm{PA}^{N}$ main effects disappeared. The interaction terms slightly improved the variance explained of the model. This improvement was borderline, but not statistically significant $(p=0.0569)$.

To test the robustness of the effect of PA on well-being against additional controls a final analysis with brands was conducted. The goal was to ensure that personality extremity, trait non-linearity, and particular trait interactions were not responsible for the effect of PA on well-being. To do this, all the variables present in Model 3, with the addition of the Big Five's quadratic functions (Lubinski \& Humphreys, 1990), the interaction between Extroversion and Neuroticism (McFatter, 1994), and personality extremity (Matz et al., 2016) (the average absolute distance from the median traits 
score), were input into a forward and backwards processing step-wise regression predicting well-being, so that all variables were in competition with one another (Lubinski \& Humphreys, 1990). A step-wise regression was chosen because of the multicollinearity between the additional control features, and the features in the model. The selected step-wise model, which can be viewed in Table 4, shows that $\mathrm{PA}^{C}, \mathrm{PA}^{E}$, $\mathrm{PA}^{A}$, and $\mathrm{PA}^{N}$ were all selected either instead of, or as well as, the additional control variables. This suggests that it is indeed the homophily effect with similar others (or 'buying what people like you buy'), not just aspects of the individual's own personality, that is important for predicting well-being.

Table 1

Sample Summary Statistics

\begin{tabular}{lllll}
\hline & \multicolumn{2}{l}{ Brand Sample } & \multicolumn{2}{l}{ Product Sample } \\
\cline { 2 - 5 } & Mean & $S D$ & Mean & $S D$ \\
\hline Age (years) & 51 & 15 & 51 & 15 \\
Avg Monthly Spend (£) & 42.77 & 30.37 & 42.74 & 30.36 \\
Openness & 4.84 & 1.19 & 4.84 & 1.18 \\
Conscientiousness & 5.84 & 1.08 & 5.84 & 1.08 \\
Extroversion & 4.03 & 1.54 & 4.02 & 1.54 \\
Agreeableness & 5.50 & 1.12 & 5.50 & 1.11 \\
Neuroticism & 3.31 & 1.46 & 3.31 & 1.46 \\
Subjective Well-being & 7.16 & 1.93 & 7.15 & 1.94 \\
\hline
\end{tabular}

Note: The Brand Sample and Product Sample are almost identical as both comprised of the majority of the people in our total surveyed population. 


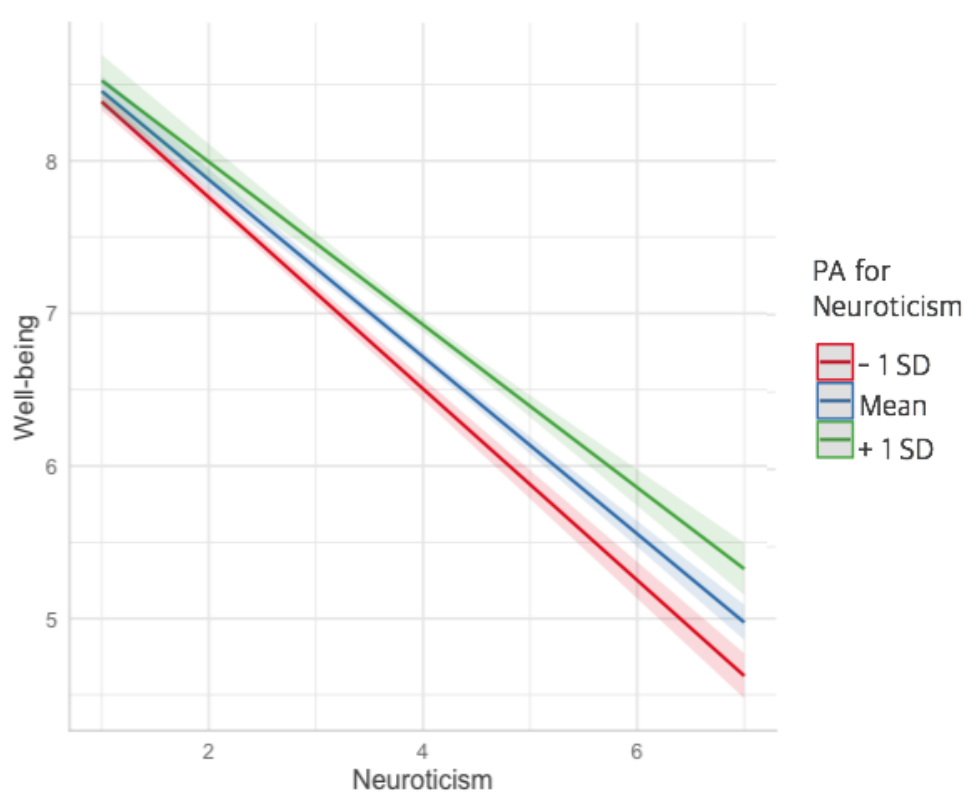

(a) Brands Analysis

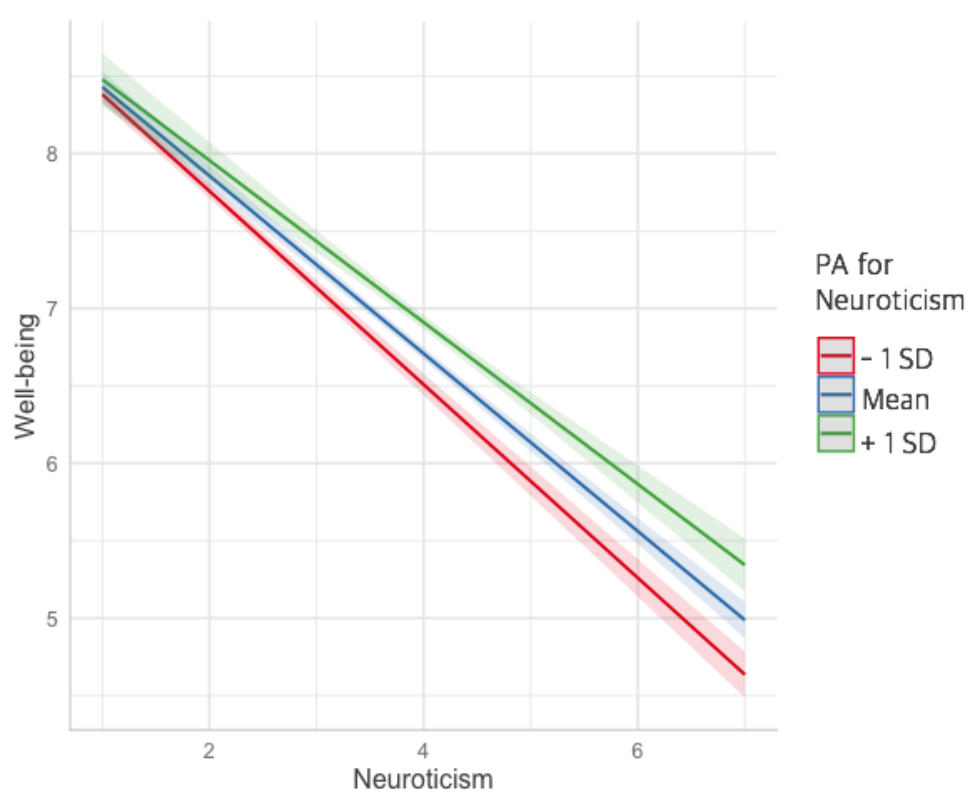

(b) Products Analysis

Figure 2. A graph to show the interaction effect between the individual's trait Neuroticism and PA for trait Neuroticism $\left(P A^{N}\right)$ on well-being, for (a) the Brands Analysis, and (b) the Products Analysis. The values plotted for $\left(P A^{N}\right)$ are the mean, the value one standard deviation above, and the value one standard deviation below the mean (Aiken, West, \& Reno, 1991).

\section{Analysis 2: Products}

Slightly more individuals $(N=12,230)$ had bought from at least one of the 100 most popular product categories than the brands categories, resulting in $3,188,290$ 
individual transactions. The mean number of product categories people bought from was $41.35(S D=17.11)$, and the mean number of products people bought in each category was $6.39(S D=14.39)$. The descriptive statistics for age, average monthly spending, the Big Five, and well-being can be found in Table 1.

To investigate how PA, expressed through the products people buy, relates to well-being, three hierarchical linear regression models were performed - using the same method of analysis that was used for brands. The variance explained by each model, the model comparisons, and the unstandardised coefficients and confidence intervals can be viewed in Table 5 .

In Model 1, with demographics, spending, and personality traits only, all variables significantly predicted well-being. In Model 2, the addition of PA on the Big Five significantly improved the model. As with the brand analysis, only $\mathrm{PA}^{E}, \mathrm{PA}^{A}$, and $\mathrm{PA}^{N}$ were significant predictors of well-being. Therefore, buying the products that people who are similar in Extroversion, Agreeableness and Neuroticism buy, predicts greater well-being. Model 3 investigated whether this effect is dependent on the individual's own personality traits. A significant interaction was found between $\mathrm{PA}^{N}$ and trait Neuroticism. Figure $2 \mathrm{~b}$ shows that, as with the brands analysis, the effect of PA on well-being was much greater for those high in Neuroticism. In other words, people high in Neuroticism were happier when they bought what other people high in Neuroticism bought. This interaction significantly $(p<0.05)$ improved the variance explained in Model 3 compared to Model 2, and when the interaction effects were included, the main effects of $\mathrm{PA}^{A}$ and $\mathrm{PA}^{N}$ disappeared.

To test the robustness of the effect of PA on well-being against additional controls (personality extremity, non-linear trait values, and the Extroversion*Neuroticism interaction effects) a final step-wise regression model was performed. The selected model can be found in Table 6. The step-wise regression shows that $\mathrm{PA}^{E}, \mathrm{PA}^{A}, \mathrm{PA}^{N}$, and $\mathrm{PA}^{O}$ (although it did not reach significance) were selected for either instead of or as well as the interactions and non-linearity's of the personality variables. 
Table 2

Exemplar product categories strongly emphasized by particular personalities (all at least 1.5 SD from the mean for the trait)

\begin{tabular}{l|l}
\hline$+O$ & Salads, Fresh Fruit, Baby Toiletries \\
$-O$ & Hand Wash, Fragrance Gifts, Body Sprays \\
$+C$ & Contact Lens, Cotton Wool, First Aid \\
$-C$ & Jewellery, Sweet Snacks, Dietary Products \\
$+E$ & Self Tan Products, Contact Lens, Tights \\
$-E$ & Sanitary Towels, Dietary Products, Incontinence Pads \\
$+A$ & Decongestant, First Aid Accessories, Denture Products \\
$-A$ & Baby Toiletries, Nappies, Formula/Milk \\
$+N$ & Sanitary Towels, Jewellery, Newspapers/Magazines \\
$-N$ & Smoking Cessation, Contact Lens, Decongestant \\
\hline
\end{tabular}

\section{Discussion}

The analysis presented shows that PA, a metric which directly captures the extent to which people exhibit personality homophily in their shopping patterns, positively predicts well-being. The findings showed that $\mathrm{PA}^{E}, \mathrm{PA}^{A}$ and $\mathrm{PA}^{N}$ predicted well-being, but $\mathrm{PA}^{O}$ and $\mathrm{PA}^{C}$ did not, suggesting that in a consumer-context personality homophily has a positive influence on well-being - but only when that homophily occurs on traits Extroversion, Agreeableness and Neuroticism. In a consumer context Openness and Conscientiousness do not seem relevant. Further, the homophily effect of $\mathrm{PA}^{N}$ on well-being was greater for those who were higher in Neuroticism. The effect of PA for traits Extroversion, Agreeableness, and Neuroticism on well-being were significant even after average monthly spending was accounted for, providing further evidence that it is not necessarily how much you spend, but what you spend your money on that matters (Dunn et al., 2011; Matz et al., 2016). Overall, these results indicate that personality homophily is not only occurring in a consumer setting, and can be measured in transaction data, but that it signifies an increase in happiness. The effect uncovered by this methodology might be leveraged by algorithms to both predict and/or encourage subjective well-being (and without any overhead of rating products, or need to manually attribute brands with human personality traits).

Examining the links between well-being and homophilous consumption behaviour (or 'buying what people like you buy'), allowed us to identify greater effect sizes than in 
related studies, which have conceptualised products themselves as having personality traits and considered 'psychological-fit' rather than homophily. Model 2 in this study, comprising of demographics, spend, personality and homophily (without the interaction terms), explained $21 \%$ of the variance in well-being (using the adjusted $R^{2}$ metric). This is notably higher than the findings in Matz et al. (2016)'s, where models were able to explain $11 \%$. That study took a mean of all traits in measuring similarity between shopping and personality, finding a combined fit coefficient of $b=0.6$, but which was no longer significant when personality was entered into the model. In contrast, this homophily study found that the significant coefficients for PA on products ranged from $b=0.08\left(\mathrm{PA}^{A}\right)$ to $b=0.16\left(\mathrm{PA}^{N}\right)$. Although direct comparisons are hard to make using different datasets, and with differences in model specifications, the increased effect sizes found in this study are highly encouraging - and lend credence to further investigation of homophily in consumer settings. We do note, however, that Matz et al. (2016)'s method focused on people's perceptions of products, and while the results of this paper speak to the design of recommender systems, in other domains such as marketing, perceptions of products may be more relevant than people's actual purchasing behaviour.

The PA metric introduced in this study is a computationally efficient way of calculating personality homophily in consumer data. Importantly, it is readily transferable to any other retail settings. It has no requirement for products or brands to be rated on their psychological characteristics. The method does still require a sample of surveyed personality scores for customers, but our analysis suggests that the ten item personality inventory (TIPI) is sufficient for this. Moreover, results also indicate that just three of the Big Five personality traits are relevant (Extroversion, Agreeableness and Neuroticism), reflecting a total of 6 questions using the TIPI. This low overhead is relevant to collaborative filtering algorithms in particular, where initial ratings are often required to alleviate the 'cold start' problem, which occurs where no behavioural data is available to calculate initial user similarities. Alternatively, once purchase data has been collected, research has shown that personality can be predicted directly from it (Gladstone, Matz, \& Lemaire, 2019). Future methodologies might harness such 
predictions to alleviate the need for a personality questionnaires to be carried out altogether.

For both brands and products, that only Extroversion, Agreeableness and Neuroticism were important to align on, contributes to the growing stream of research on personality homophily and well-being. Our findings align with Noë et al. (2018)'s study which found a geographic homophily effect for Extroversion and negative effects for Openness and Conscientiousness. The results also overlap with studies of social networks that have found that dimensions of Agreeableness and Extraversion engendered homophily effects, with similar pairs showing stronger connections (Noë, Whitaker, \& Allen, 2016). Our findings do however contrast with Jokela et al. (2015)'s study which found a geographic homophily effect for Openness was related to increased well-being. This highlights that the personality homophily effect on well-being for individual traits is likely context dependent (i.e. choosing where to live is underpinned by different psychological processes/motives in comparison to choosing what to buy/which daily locations to frequent). Further research is needed to understand the effect of personality homophily on well-being in different these domains, and whether other commonalities run throughout.

In Model 3, for both brands and products, the interactions between PA and the person's personality showed that the effect of $\mathrm{PA}^{N}$ on well-being is much stronger for neurotic people than emotionally stable people. The stronger effect of PA on well-being for individuals high in Neuroticism could be explained by people with greater mood instability using consumption to cheer themselves up. Products high in Neuroticism in this dataset included jewellery, magazines, and sweet snacks - all of which could be used to temporarily alleviate negative affect. In comparison, the effect of PA on well-being was found to be equal for both introverts and extroverts: introverts were happiest when they bought products/brands that other introverts bought, and extroverts were happiest when they bought items that other extroverts had purchased. Further research could use questionnaires and experience sampling methods to study the effect of purchase-induced moods on well-being over time. 
Analyses also found strong commonalities across two different types of spending: the purchasing of brands, and the purchasing in product categories. Personality alignment on both brands and products were significant predictors of well-being, with similar effect sizes, and PA on identical traits (Extroversion, Agreeableness, and Neuroticism) being identified as important. This is despite the fact that brands and products represent extremely different item groupings, and brands having a history of being associated with human psychological traits (Aaker, 1997; Avis, Forbes, \& Ferguson, 2014; Sirgy, 1985). This suggests that there is something about homophily and personality alignment itself, rather than specific characteristics of items bought, that contributes to increased well-being. The present results are correlational, and there remains a statistical challenge in resolving whether happier people buy in line with their personality, or whether the alignment towards those of a similar personality itself engenders increased well-being. It is also possible that both exist in a reciprocal fashion, as observed with personality and well-being in Soto (2015).

As well as providing data in abundance, a further advantage of using transaction data is that it constitutes a measure of real world behaviour, unbiased by social desirability (Van de Mortel et al., 2008) or miss-remembering (Jakovcevic et al., 2014). A limitation of working with such data, however, is it's assumed the individual's personality is related to every purchase they buy. However, it is to be expected that people are also buying items for other people - something which cannot be controlled for here. Although the literature on personality homophily suggests that friends and partners have similar personalities (Wu et al., 2017), and these people are likely to be for whom customers are buying for, purchasing for other people will still introduce noise into the data - contributing to smaller effect sizes that would be expected from a lab or field experiment with more controls (Matz, Gladstone, \& Stillwell, 2017).

The effect this study uncovered, that people who exhibit personality homophily in their shopping patterns are happier, is a principle that could practically, and perhaps responsibly, be harnessed by CF algorithms (Khwaja et al., 2019; Tkalcic et al., 2009) given their increasing influence over consumer-decision making. Whilst CF traditionally 
optimise likelihood of sale, these results show that systems built using PA could optimised for both purchases and longer term customer well-being - something which is highly relevant given the growing attention to ethical AI (Floridi et al., 2018). In addition, compared to other measures which examine the connection between personality and well-being, the data-derived technique presented in this study is: more efficient than comparable approaches (it does not require extra data collection); it is less subjective (not relying on the personification of objects); it has the potential for further automation (EPP can be dynamically updated, as the products that are synonymous with certain personality types evolve over time); and while we use product and brand categories in this analysis, the technique presented is readily extensible to the level of individual items (if computational capacity is available).

Despite the smaller effect sizes commonly being found in big data analyses (Boyce, Daly, Hounkpatin, \& Wood, 2017; Matz, Gladstone, \& Stillwell, 2017), clear indication of personality homophily's relationship to well-being were found in this study (whilst controlling for demographics, total spend, income, individual's personality, and indeed additional personality controls), highlighting the potential for further investigation in a consumer domain. One would not expect consumption to affect well-being more than other established effects such as Extroversion and Neuroticism, but that such a signal for the influence of homophily on well-being is identifiable, provides a useful basis for understanding how we as consumers can get the best from our consumption decisions. Overall, this study provides compelling evidence not only that 'birds of a feather, shop together', but that those people making purchasing decisions in harmony with others of the same personality will, in general, exhibit greater well-being. 
Table 3

Hierarchical linear regressions using PA on brands to predict well-being

\begin{tabular}{|c|c|c|c|}
\hline & \multicolumn{3}{|c|}{ Subjective Well-being } \\
\hline & Mode 1 & Model 2 & Model 3 \\
\hline Age (years) & $0.01^{* * *}(0.01,0.02)$ & $0.01^{* * *}(0.01,0.02)$ & $0.01^{* * *}(0.01,0.02)$ \\
\hline Gender: Male & $-0.32^{* * *}(-0.43,-0.21)$ & $-0.31^{* * *}(-0.42,-0.19)$ & $-0.31^{* * *}(-0.42,-0.19)$ \\
\hline Income: $£ 25,000$ to $£ 34,999$ & $0.35^{* * *}(0.26,0.45)$ & $0.35^{* * *}(0.25,0.45)$ & $0.35^{* * *}(0.25,0.45)$ \\
\hline Income: $£ 35,000$ to $£ 49,999$ & $0.54^{* * *}(0.44,0.64)$ & $0.53^{* * *}(0.43,0.63)$ & $0.53^{* * *}(0.43,0.63)$ \\
\hline Income: $£ 50,000$ to $£ 74,999$ & $0.51^{* * *}(0.40,0.61)$ & $0.50^{* * *}(0.40,0.61)$ & $0.51^{* * *}(0.40,0.61)$ \\
\hline Income: $£ 75,000$ to $£ 99,999$ & $0.60^{* * *}(0.45,0.74)$ & $0.59^{* * *}(0.44,0.74)$ & $0.60^{* * *}(0.45,0.74)$ \\
\hline Income: $£ 100,000$ to $£ 149,999$ & $0.55^{* * *}(0.36,0.75)$ & $0.56^{* * *}(0.37,0.75)$ & $0.56^{* * *}(0.37,0.76)$ \\
\hline Income: $£ 150,000$ or more & $0.55^{* * *}(0.27,0.83)$ & $0.57^{* * *}(0.29,0.85)$ & $0.57^{* * *}(0.29,0.85)$ \\
\hline Income: Prefer not to say & $0.52^{* * *}(0.42,0.61)$ & $0.50^{* * *}(0.41,0.59)$ & $0.50^{* * *}(0.41,0.60)$ \\
\hline$(\log )$ Average Monthly Spend $(£)$ & $0.09^{* * *}(0.04,0.14)$ & $0.09^{* * *}(0.05,0.14)$ & $0.09^{* * *}(0.04,0.14)$ \\
\hline Openness & $-0.04^{* *}(-0.07,-0.02)$ & $-0.05^{* *}(-0.09,-0.01)$ & $-0.05^{*}(-0.09,-0.01)$ \\
\hline Conscientousness & $0.13^{* * *}(0.10,0.16)$ & $0.13^{* * *}(0.09,0.17)$ & $0.13^{* * *}(0.08,0.17)$ \\
\hline Extroversion & $0.13^{* * *}(0.11,0.15)$ & $0.16^{* * *}(0.14,0.19)$ & $0.15^{* * *}(0.12,0.18)$ \\
\hline Agreeableness & $0.05^{* * *}(0.02,0.08)$ & $0.10^{* * *}(0.05,0.14)$ & $0.09^{* * *}(0.05,0.14)$ \\
\hline Neuroticism & $-0.44^{* * *}(-0.46,-0.41)$ & $-0.51^{* * *}(-0.53,-0.48)$ & $-0.48^{* * *}(-0.51,-0.44)$ \\
\hline$P A^{O}$ & & $-0.02(-0.08,0.03)$ & $-0.02(-0.19,0.16)$ \\
\hline$P A^{C}$ & & $-0.01(-0.06,0.05)$ & $0.06(-0.18,0.30)$ \\
\hline$P A^{E}$ & & $0.08^{* * *}(0.04,0.12)$ & $0.16^{* *}(0.04,0.28)$ \\
\hline$P A^{A}$ & & $0.07^{*}(0.01,0.13)$ & $0.09(-0.13,0.32)$ \\
\hline$P A^{N}$ & & $0.17^{* * *}(0.13,0.22)$ & $0.03(-0.08,0.14)$ \\
\hline Openness* $P A^{O}$ & & & $-0.001(-0.04,0.03)$ \\
\hline Conscientiousness ${ }^{*} P A^{C}$ & & & $-0.01(-0.06,0.03)$ \\
\hline Extroversion ${ }^{*} P A^{E}$ & & & $-0.02(-0.04,0.01)$ \\
\hline Agreeableness* $P A^{A}$ & & & $-0.004(-0.05,0.04)$ \\
\hline Neuroticism* $P A^{N}$ & & & $0.04^{* *}(0.01,0.07)$ \\
\hline Observations & 12,167 & 12,167 & 12,167 \\
\hline $\mathrm{R}^{2}$ & 0.208 & 0.214 & 0.215 \\
\hline Adjusted $\mathrm{R}^{2}$ & 0.207 & 0.213 & 0.213 \\
\hline Residual Std. Error & $1.72(d f=12151)$ & $1.71(d f=12146)$ & $1.71(d f=12141)$ \\
\hline F statistic: & $F(15,12151)=212.40^{* * *}$ & $F(20,12146)=165.6^{* * *}$ & $F(25,12141)=134.01^{* * *}$ \\
\hline Model Comparison & & $X^{2}(5)=279.85^{* * *}$ & $X^{2}(5)=31.501, p=0.0569$ \\
\hline
\end{tabular}

Note: Significance levels: ${ }^{*} p<0.05 ;{ }^{* *} p<0.01 ;{ }^{* * *} p<0.001$. Coefficients are unstandardised $b . d f=$ degrees of freedom. 
Table 4

Forwards and backwards processing step-wise regression with PA on brands predicting well-being

Age (years)

Gender: Male

Income: $£ 25,000$ to $£ 34,999$

Income: $£ 35,000$ to $£ 49,999$

Income: $£ 50,000$ to $£ 74,999$

Income: $£ 75,000$ to $£ 99,999$

Income: $£ 100,000$ to $£ 149,999$

Income: $£ 150,000$ or more

Income: Prefer not to say

(log) Average Monthly Spend (£)

Openness

Conscientousness

Extroversion

Agreeableness

Neuroticism

$\mathrm{PA}^{C}$

$\mathrm{PA}^{E}$

$\mathrm{PA}^{A}$

$\mathrm{PA}^{N}$

Conscientousness $^{2}$

Agreeableness $^{2}$

Neuroticism $* \mathrm{PA}^{N}$

Extroversion*Neuroticism
Subjective Well-being

$0.01^{* * *}(0.01,0.02)$

$-0.31^{* * *}(-0.42,-0.20)$

$0.35^{* * *}(0.25,0.45)$

$0.53^{* * *}(0.43,0.63)$

$0.50^{* * *}(0.40,0.61)$

$0.59^{* * *}(0.44,0.74)$

$0.56^{* * *}(0.37,0.75)$

$0.57^{* * *}(0.29,0.85)$

$0.50^{* * *}(0.41,0.60)$

$0.09^{* * *}(0.04,0.14)$

$-0.04^{* *}(-0.07,-0.01)$

$-0.50(-1.13,0.13)$

$0.11^{* * *}(0.05,0.16)$

$0.16(-0.31,0.63)$

$0.17(-0.02,0.36)$

$0.07^{* * *}(0.03,0.11)$

$0.10^{* *}(0.03,0.16)$

$-0.38^{* *}(-0.66,-0.10)$

$0.07^{*}(0.0000,0.13)$

$0.01^{* * *}(0.01,0.02)$

$-0.08^{* *}(-0.13,-0.03)$

$0.09^{* * *}(0.05,0.13)$

$0.02 *(0.002,0.03)$

Observations

$\mathrm{R}^{2}$

\section{2,167}

0.216

Adjusted $\mathrm{R}^{2}$

0.215

Residual Std. Error

$1.71(d f=12143)$

F Statistic

$F(23,12143)=145.42^{* * *}$

Coefficients are unstandardised $b$. Significance levels are ${ }^{*} p<0.05 ;{ }^{* *} p<0.01 ;{ }^{* * *} p<0.001$. df $=$ degrees of freedom. Note that the effect of $\mathrm{PA}^{A}$ is reversed, attributed to multicollinearity in the model. N's interaction with $\mathrm{PA}^{N}$ stays significant. The variables that were not selected were: Personality Extremity, $\mathrm{PA}^{O}, \mathrm{O}^{2}, \mathrm{E}^{2}, \mathrm{~N}^{2}, \mathrm{O}^{*} \mathrm{PA}^{O}, \mathrm{C}^{*} \mathrm{PA}^{C}, \mathrm{E}^{*} \mathrm{PA}^{E}$, and $\mathrm{A}^{*} \mathrm{PA}^{A}$. 
Table 5

Hierarchical linear regressions using $P A$ on products to predict subjective well-being

\begin{tabular}{|c|c|c|c|}
\hline & \multicolumn{3}{|c|}{ Subjective Well-being } \\
\hline & Mode 1 & Model 2 & Model 3 \\
\hline Age (years) & $0.01^{* * *}(0.01,0.02)$ & $0.01^{* * *}(0.01,0.02)$ & $0.01^{* * *}(0.01,0.02)$ \\
\hline Gender: Male & $-0.32^{* * *}(-0.43,-0.21)$ & $-0.30^{* * *}(-0.42,-0.19)$ & $-0.30^{* * *}(-0.42,-0.19)$ \\
\hline Income: $£ 25,000$ to $£ 34,999$ & $0.37^{* * *}(0.27,0.47)$ & $0.36^{* * *}(0.27,0.46)$ & $0.37^{* * *}(0.27,0.47)$ \\
\hline Income: $£ 35,000$ to $£ 49,999$ & $0.55^{* * *}(0.45,0.65)$ & $0.54^{* * *}(0.44,0.64)$ & $0.55^{* * *}(0.45,0.65)$ \\
\hline Income: $£ 50,000$ to $£ 74,999$ & $0.51^{* * *}(0.41,0.62)$ & $0.51^{* * *}(0.41,0.62)$ & $0.52^{* * *}(0.41,0.63)$ \\
\hline Income: $£ 75,000$ to $£ 99,999$ & $0.61^{* * *}(0.46,0.75)$ & $0.60^{* * *}(0.45,0.75)$ & $0.61^{* * *}(0.46,0.75)$ \\
\hline Income: $£ 100,000$ to $£ 149,999$ & $0.56^{* * *}(0.36,0.75)$ & $0.57^{* * *}(0.38,0.76)$ & $0.57^{* * *}(0.38,0.77)$ \\
\hline Income: $£ 150,000$ or more & $0.56^{* * *}(0.27,0.84)$ & $0.58^{* * *}(0.30,0.86)$ & $0.57^{* * *}(0.29,0.85)$ \\
\hline Income: Prefer not to say & $0.50^{* * *}(0.40,0.59)$ & $0.48^{* * *}(0.39,0.58)$ & $0.49^{* * *}(0.39,0.58)$ \\
\hline (log) Average Monthly Spend $(£)$ & $0.08^{* *}(0.03,0.12)$ & $0.08^{* * *}(0.03,0.13)$ & $0.08^{* *}(0.03,0.13)$ \\
\hline Openness & $-0.04^{* *}(-0.07,-0.01)$ & $-0.05^{* *}(-0.09,-0.02)$ & $-0.05^{*}(-0.09,-0.01)$ \\
\hline Conscientousness & $0.13^{* * *}(0.10,0.16)$ & $0.13^{* * *}(0.09,0.17)$ & $0.12^{* * *}(0.08,0.17)$ \\
\hline Extroversion & $0.14^{* * *}(0.11,0.16)$ & $0.17^{* * *}(0.14,0.20)$ & $0.16^{* * *}(0.13,0.19)$ \\
\hline Agreeableness & $0.04^{* *}(0.01,0.07)$ & $0.09^{* * *}(0.05,0.14)$ & $0.10^{* * *}(0.05,0.14)$ \\
\hline Neuroticism & $-0.44^{* * *}(-0.46,-0.41)$ & $-0.50^{* * *}(-0.53,-0.47)$ & $-0.47^{* * *}(-0.51,-0.44)$ \\
\hline $\mathrm{PA}^{O}$ & & $-0.04(-0.09,0.01)$ & $-0.05(-0.23,0.12)$ \\
\hline $\mathrm{PA}^{C}$ & & $-0.01(-0.07,0.05)$ & $0.11(-0.13,0.35)$ \\
\hline $\mathrm{PA}^{E}$ & & $0.09^{* * *}(0.05,0.13)$ & $0.14^{*}(0.02,0.27)$ \\
\hline $\mathrm{PA}^{A}$ & & $0.08^{* *}(0.02,0.14)$ & $0.05(-0.18,0.27)$ \\
\hline $\mathrm{PA}^{N}$ & & $0.16^{* * *}(0.12,0.20)$ & $0.002(-0.11,0.11)$ \\
\hline Openness ${ }^{*} \mathrm{PA}^{O}$ & & & $0.003(-0.03,0.04)$ \\
\hline Conscientousness ${ }^{*} \mathrm{PA}^{C}$ & & & $-0.02(-0.07,0.02)$ \\
\hline Extroversion ${ }^{*} \mathrm{PA}^{E}$ & & & $-0.01(-0.04,0.01)$ \\
\hline Agreeableness ${ }^{*} \mathrm{PA}^{A}$ & & & $0.01(-0.04,0.05)$ \\
\hline Neuroticism* $^{*} \mathrm{PA}^{N}$ & & & $0.05^{* *}(0.02,0.08)$ \\
\hline Observations & 12,230 & 12,230 & 12,230 \\
\hline $\mathrm{R}^{2}$ & 0.21 & 0.21 & 0.21 \\
\hline Adjusted $\mathrm{R}^{2}$ & 0.20 & 0.21 & 0.21 \\
\hline Residual Std. Error & $1.73(\mathrm{df}=12214)$ & $1.72(\mathrm{df}=12209)$ & $1.72(\mathrm{df}=12204)$ \\
\hline F Statistic & $F(15,12214)=210.38^{* * *}$ & $F(20,12209)=163.69^{* * *}$ & $F(25,12204)=131.53^{* * *}$ \\
\hline Model Comparison & & $X^{2}(5)=281.29^{* * *}$ & $X^{2}(5)=36.566^{*}$ \\
\hline
\end{tabular}

Note: Significance levels: ${ }^{*} p<0.05 ;{ }^{* *} p<0.01 ;{ }^{* * *} p<0.001$. Coefficients are unstandardised $b . d f=$ degrees of freedom. 
Table 6

Forwards and backwards processing step-wise regression with PA on products predicting well-being

\begin{tabular}{|c|c|}
\hline & Subjective Well-being \\
\hline Age (years) & $0.01^{* * *}(0.01,0.02)$ \\
\hline Gender: Male & $-0.31^{* * *}(-0.42,-0.19)$ \\
\hline Income: $£ 25,000$ to $£ 34,999$ & $0.36^{* * *}(0.27,0.46)$ \\
\hline Income: $£ 35,000$ to $£ 49,999$ & $0.54^{* * *}(0.44,0.64)$ \\
\hline Income: $£ 50,000$ to $£ 74,999$ & $0.51^{* * *}(0.40,0.62)$ \\
\hline Income: $£ 75,000$ to $£ 99,999$ & $0.60^{* * *}(0.45,0.74)$ \\
\hline Income: $£ 100,000$ to $£ 149,999$ & $0.57^{* * *}(0.37,0.76)$ \\
\hline Income: $£ 150,000$ or more & $0.58^{* * *}(0.29,0.86)$ \\
\hline Income: Prefer not to say & $0.49^{* * *}(0.39,0.58)$ \\
\hline (log) Average Monthly Spend (£) & $0.08^{* *}(0.03,0.13)$ \\
\hline Openness & $-0.05^{* *}(-0.09,-0.02)$ \\
\hline Extroversion & $0.11^{* * *}(0.05,0.17)$ \\
\hline Agreeableness & $0.09^{* * *}(0.05,0.14)$ \\
\hline Neuroticism & $0.30(-0.17,0.78)$ \\
\hline $\mathrm{PA}^{O}$ & $-0.04(-0.09,0.01)$ \\
\hline $\mathrm{PA}^{E}$ & $0.08^{* * *}(0.04,0.12)$ \\
\hline $\mathrm{PA}^{A}$ & $0.08^{* *}(0.02,0.14)$ \\
\hline $\mathrm{PA}^{N}$ & $-0.48^{* * *}(-0.77,-0.20)$ \\
\hline Conscientiousness $^{2}$ & $0.01^{* * *}(0.01,0.02)$ \\
\hline Neuroticism $^{2}$ & $-0.10^{* * *}(-0.15,-0.04)$ \\
\hline Neuroticism* $\mathrm{PA}^{N}$ & $0.10^{* * *}(0.06,0.14)$ \\
\hline Extroversion*Neuroticism & $0.02^{*}(0.002,0.03)$ \\
\hline Observations & 12,230 \\
\hline $\mathrm{R}^{2}$ & 0.21 \\
\hline Adjusted $\mathrm{R}^{2}$ & 0.21 \\
\hline Residual Std. Error & $1.72(d f=12207)$ \\
\hline F Statistic & $F(22,12207)=150.48^{* * *}$ \\
\hline
\end{tabular}

Coefficients are unstandardised $b$. Significance levels are ${ }^{*} p<0.05 ;{ }^{* *} p<0.01 ;{ }^{* * *} p<0.001$. $d f=$ degrees of freedom. Note that $\mathrm{PA}^{N}$ 's effect is reversed, attributed to multicollinearity in the model. The interaction effect $\mathrm{N}: \mathrm{PA}^{N}$ remained a strong significant predictor. The interaction between Extroversion and Neuroticism was also significant. The variables that were not selected were: Conscientiousness, Personality Extremity, $\mathrm{PA}^{C}$, Openness ${ }^{2}$, Extroversion ${ }^{2}$, Agreeableness $^{2}$, Openness $^{*} \mathrm{PA}^{O}$, Conscientiousness $^{*} \mathrm{PA}^{C}$, Extroversion*PA ${ }^{E}$, and Agreeableness* ${ }^{*} A^{A}$ 


\section{References}

Aaker, J. L. (1997). Dimensions of brand personality. Journal of marketing research, $347-356$.

Aiken, L. S., West, S. G., \& Reno, R. R. (1991). Multiple regression: Testing and interpreting interactions. sage.

Avis, M., Forbes, S., \& Ferguson, S. (2014). The brand personality of rocks: A critical evaluation of a brand personality scale. Marketing Theory, 14(4), 451-475.

Boyce, C. J., Daly, M., Hounkpatin, H. O., \& Wood, A. M. (2017). Money may buy happiness, but often so little that it doesn't matter. Psychological science, 28(4), $544-546$.

Costa, P. T., \& McCrae, R. R. (1985). The neo personality inventory. Psychological Assessment Resources Odessa, FL.

Diener, E., \& Seligman, M. E. (2004). Beyond money: Toward an economy of well-being. Psychological science in the public interest, 5(1), 1-31.

Dunn, E. W., Gilbert, D. T., \& Wilson, T. D. (2011). If money doesn’t make you happy, then you probably aren't spending it right. Journal of Consumer Psychology, 21(2), 115-125.

Floridi, L., Cowls, J., Beltrametti, M., Chatila, R., Chazerand, P., Dignum, V., ... others (2018). Ai4people - an ethical framework for a good ai society: opportunities, risks, principles, and recommendations. Minds and Machines, 28(4), 689-707.

Frischmann, B., \& Selinger, E. (2018). Re-engineering humanity. Cambridge University Press.

Gilovich, T., Kumar, A., \& Jampol, L. (2015a). The beach, the bikini, and the best buy: Replies to dunn and weidman, and to schmitt, brakus, and zarantonello. Journal of Consumer Psychology, 25(1), 179-184.

Gilovich, T., Kumar, A., \& Jampol, L. (2015b). A wonderful life: Experiential consumption and the pursuit of happiness. Journal of Consumer Psychology, $25(1), 152-165$. 
Gladstone, J. J., Matz, S. C., \& Lemaire, A. (2019). Can psychological traits be inferred from spending? evidence from transaction data. Psychological science, 0956797619849435.

Goldberg, L. R. (1992). The development of markers for the big-five factor structure. Psychological assessment, 4(1), 26.

Gosling, S. D., Rentfrow, P. J., \& Swann Jr, W. B. (2003). A very brief measure of the big-five personality domains. Journal of Research in personality, 37(6), 504-528.

Heine, S. J., Lehman, D. R., Peng, K., \& Greenholtz, J. (2002). What's wrong with cross-cultural comparisons of subjective likert scales?: The reference-group effect. Journal of personality and social psychology, 82(6), 903.

Hill, G., \& Howell, R. T. (2014). Moderators and mediators of pro-social spending and well-being: The influence of values and psychological need satisfaction. Personality and Individual Differences, 69, 69-74.

Jakovcevic, A., Steg, L., Mazzeo, N., Caballero, R., Franco, P., Putrino, N., \& Favara, J. (2014). Charges for plastic bags: Motivational and behavioral effects. Journal of Environmental Psychology, 40, 372-380.

Jokela, M., Bleidorn, W., Lamb, M. E., Gosling, S. D., \& Rentfrow, P. J. (2015). Geographically varying associations between personality and life satisfaction in the london metropolitan area. Proceedings of the National Academy of Sciences, $112(3), 725-730$.

Khwaja, M., Ferrer, M., Iglesias, J. O., Faisal, A. A., \& Matic, A. (2019). Aligning daily activities with personality: towards a recommender system for improving wellbeing. In Proceedings of the 13th acm conference on recommender systems (pp. 368-372).

Laakasuo, M., Rotkirch, A., van Duijn, M., Berg, V., Jokela, M., David-Barrett, T., ... Dunbar, R. (2020). Homophily in personality enhances group success among real-life friends. Frontiers in Psychology, 11.

Linden, G., Smith, B., \& York, J. (2003). Amazon. com recommendations: Item-to-item collaborative filtering. IEEE Internet computing, 7(1), 76-80. 
Longo, Y., Coyne, I., Joseph, S., \& Gustavsson, P. (2016). Support for a general factor of well-being. Personality and Individual Differences, 100, 68-72.

Lubinski, D., \& Humphreys, L. G. (1990). Assessing spurious" moderator effects": Illustrated substantively with the hypothesized (" synergistic") relation between spatial and mathematical ability. Psychological bulletin, 107(3), 385.

Matz, S. C., Gladstone, J. J., \& Stillwell, D. (2016). Money buys happiness when spending fits our personality. Psychological science, 27(5), 715-725.

Matz, S. C., Gladstone, J. J., \& Stillwell, D. (2017). In a world of big data, small effects can still matter: a reply to boyce, daly, hounkpatin, and wood (2017). Psychological science, 28(4), 547-550.

Matz, S. C., Kosinski, M., Nave, G., \& Stillwell, D. J. (2017). Psychological targeting as an effective approach to digital mass persuasion. Proceedings of the national academy of sciences, 114(48), 12714-12719.

Matz, S. C., Segalin, C., Stillwell, D., Müller, S. R., \& Bos, M. W. (2019). Predicting the personal appeal of marketing images using computational methods. Journal of Consumer Psychology, 29(3), 370-390.

McCrae, R. R., \& John, O. P. (1992). An introduction to the five-factor model and its applications. Journal of personality, 60(2), 175-215.

McFatter, R. M. (1994). Interactions in predicting mood from extraversion and neuroticism. Journal of personality and social psychology, 66(3), 570.

McPherson, M., Smith-Lovin, L., \& Cook, J. M. (2001). Birds of a feather: Homophily in social networks. Annual review of sociology, 27(1), 415-444.

Noë, N., Whitaker, R. M., \& Allen, S. M. (2016). Personality homophily and the local network characteristics of facebook. In 2016 ieee/acm international conference on advances in social networks analysis and mining (asonam) (pp. 386-393).

Noë, N., Whitaker, R. M., \& Allen, S. M. (2018). Personality homophily and geographic distance in facebook. Cyberpsychology, Behavior, and Social Networking, 21(6), 361-366.

Noë, N., Whitaker, R. M., Chorley, M. J., \& Pollet, T. V. (2016). Birds of a feather 
locate together? foursquare checkins and personality homophily. Computers in Human Behavior, 58, 343-353.

Pham, M. T. (2015). On consumption happiness: A research dialogue. Journal of Consumer Psychology, 25(1), 150-151.

Rushton, J. P., \& Bons, T. A. (2005). Mate choice and friendship in twins: evidence for genetic similarity. Psychological Science, 16(7), 555-559.

Saucier, G. (1994). Mini-markers: A brief version of goldberg's unipolar big-five markers. Journal of personality assessment, 63(3), 506-516.

Schmitt, B., Brakus, J. J., \& Zarantonello, L. (2015). From experiential psychology to consumer experience. Journal of Consumer Psychology, 25(1), 166-171.

Sirgy, M. J. (1985). Using self-congruity and ideal congruity to predict purchase motivation. Journal of business Research, 13(3), 195-206.

Smith, A. (2019). Consumer behaviour and analytics: Data driven decision making. Routledge.

Soto, C. J. (2015). Is happiness good for your personality? concurrent and prospective relations of the big five with subjective well-being. Journal of personality, 83(1), $45-55$.

Su, X., \& Khoshgoftaar, T. M. (2009). A survey of collaborative filtering techniques. Advances in artificial intelligence, 2009.

Tkalcic, M., Kunaver, M., Tasic, J., \& Košir, A. (2009). Personality based user similarity measure for a collaborative recommender system. In Proceedings of the 5th workshop on emotion in human-computer interaction-real world challenges (pp. 30-37).

Van de Mortel, T. F., et al. (2008). Faking it: social desirability response bias in self-report research. Australian Journal of Advanced Nursing, The, 25(4), 40.

Wu, Y., Stillwell, D., Schwartz, H. A., \& Kosinski, M. (2017). Birds of a feather do flock together: Behavior-based personality-assessment method reveals personality similarity among couples and friends. Psychological science, 28(3), 276-284.

Zhang, J. W., Howell, R. T., Caprariello, P. A., \& Guevarra, D. A. (2014). Damned if 
they do, damned if they don't: Material buyers are not happier from material or experiential consumption. Journal of Research in Personality, 50, 71-83. 